\title{
Climate change impact assessment on water security in South Africa: A case study in a semi-arid river basin
}

\author{
Yali Woyessa ${ }^{1, *}$ \\ ${ }^{1}$ Department of Civil Engineering, Central University of Technology, Free State, Private \\ Bag X20539, Bloemfontein 9300, South Africa
}

\begin{abstract}
The main aim of this paper is to assess the impact of regional climate change scenarios on the availability of water resources in a semiarid river basin in South Africa using a hydrological model called Soil and Water Assessment Tool (SWAT). In this paper, climate change data was derived from two downscaling approaches, namely statistical downscaling experiment (SDE) and dynamic downscaling (CORDEX). These were derived from the GCM simulations of the Coupled Model Intercomparison Project Phase-5 (CMIP5) and across two greenhouse gas emission scenarios known as Representative Concentration Pathways (RCP) 4.5 and 8.5. The spatial resolution of the dataset for the SDE method is $25 \mathrm{~km} \times 25 \mathrm{~km}$ and $50 \mathrm{~km} \times 50 \mathrm{~km}$ for the CORDEX method. Six GCM models were used for SDE set of data and four for the CORDEX set of data. SWAT model was run using these data for a period of up to mid-century $(2020$ - 2050) for SDE and for a period of up to the end of this century $(2020-2100)$ for CORDEX data. The results were then compared with long-term historical data (1975-2005). Comparison of measured data with simulated historical data showed strong correlation $\left(\mathrm{R}^{2}\right.$ $=0.95$ for $\mathrm{SDE}$ data and $\mathrm{R}^{2}=0.92$ for CORDEX data), which is indicative of the reliability of projected future climate.
\end{abstract}

\section{Introduction}

Water security is understood to be the availability of an acceptable quantity and quality of water for health, livelihoods, ecosystems and production, coupled with an acceptable level of water-related risks to people, the environment and economies [1]. The problem of water scarcity is likely to deepen according to some projected climate change scenarios. It is projected that, by 2050, the Southern African region will be generally drier [2]. In general, for South Africa there is a tendency towards a rise in temperature as evidenced in the past five decades [3]. Maximum and minimum temperatures have also shown significant increases annually, and in almost all seasons. High temperature extremes have increased significantly in frequency, and low temperatures have decreased significantly in frequency annually and in most seasons across the country [2].

\footnotetext{
* Corresponding author: ywoyessa@cut.ac.za
} 
Recent climate projections suggest a drop of up to $10 \%$ in precipitation in most of southern Africa by 2050 [4]. It is estimated that by the year 2025 almost one-half of the world population will be living in water stressed regions [5], with rapid population increase, industrialization and pollution putting further strain on the available and diminishing fresh water resources. Within this context, there is a general consensus that development has to be sustainable, adaptable and resilient to these global changes such as climate change. Resilient development involves initiatives that will deliver benefits under all potential future circumstances related to environmental changes [1]. Therefore, this calls for innovative strategic approaches to deliver water security and resilient development. The main aim of this paper is to investigate impact of climate change scenarios on water resources and water security.

\section{Methodology}

The research focused on a semi-arid river basin in the central region of South Africa, known as the Modder river basin. The Modder river basin is a large basin with a total area of 1.73 million hectares and divided into three sub-basins, namely the Upper Modder, the Middle Modder and the Lower Modder. It is located within the Upper Orange Water Management Area to the east of the city of Bloemfontein. The water supply to the middle and lower reaches of the Modder River is stabilized by two dams known as the Rustfontein and Mockes dams in the east, and by Krugersdrift Dam in the west of the city of Bloemfontein.

Climate change data was derived from two downscaling approaches, namely statistical downscaling experiment (SDE) and dynamic downscaling (CORDEX). The downscaled data were derived from the GCM simulations of the Coupled Model Inter-comparison Project Phase-5 (CMIP5) and across two greenhouse gas emission scenarios known as Representative Concentration Pathways (RCP) 4.5 and 8.5. The spatial resolution of the dataset for the SDE method is $25 \mathrm{~km} \times 25 \mathrm{~km}$ and for the CORDEX method it is $50 \mathrm{~km} \times$ $50 \mathrm{~km}$. Six GCM models were used for SDE set of data and four for the CORDEX set of data. SWAT model was run using these data for a period of up to mid-century (2020 $2050)$ for SDE and for a period of up to the end of this century $(2020-2100)$ for CORDEX data.

\section{Results and Discussion}

Comparison of measured and simulated historical values are shown in Figures 1a and $1 \mathrm{~b}$ for the SDE approach and the CORDEX approach, respectively, for the period of 1975 to 2005. Figures $2 \mathrm{a}$ and $2 \mathrm{~b}$ show the correlation between these values for SDE and CORDEX approaches over the same period. In Figures $2 \mathrm{a}$ and $2 \mathrm{~b}$, the blue points represent the observed versus simulated values whereas the blue broken line shows the linear fit between the observed and simulated values. The solid black line represents the one-to-one line (the perfect fit scenario). In both cases, the relationship between these two variables (measured and simulated historical values) are found to be strong with $\mathrm{R}^{2}>0.92$. The purpose of simulating the historical data was to compare with climate observations over a common period and use information derived from the comparison to adjust future climate projections so that they are (progressively) more consistent with the historical climate records and, presumably, more realistic for the spatial domain of interest. 

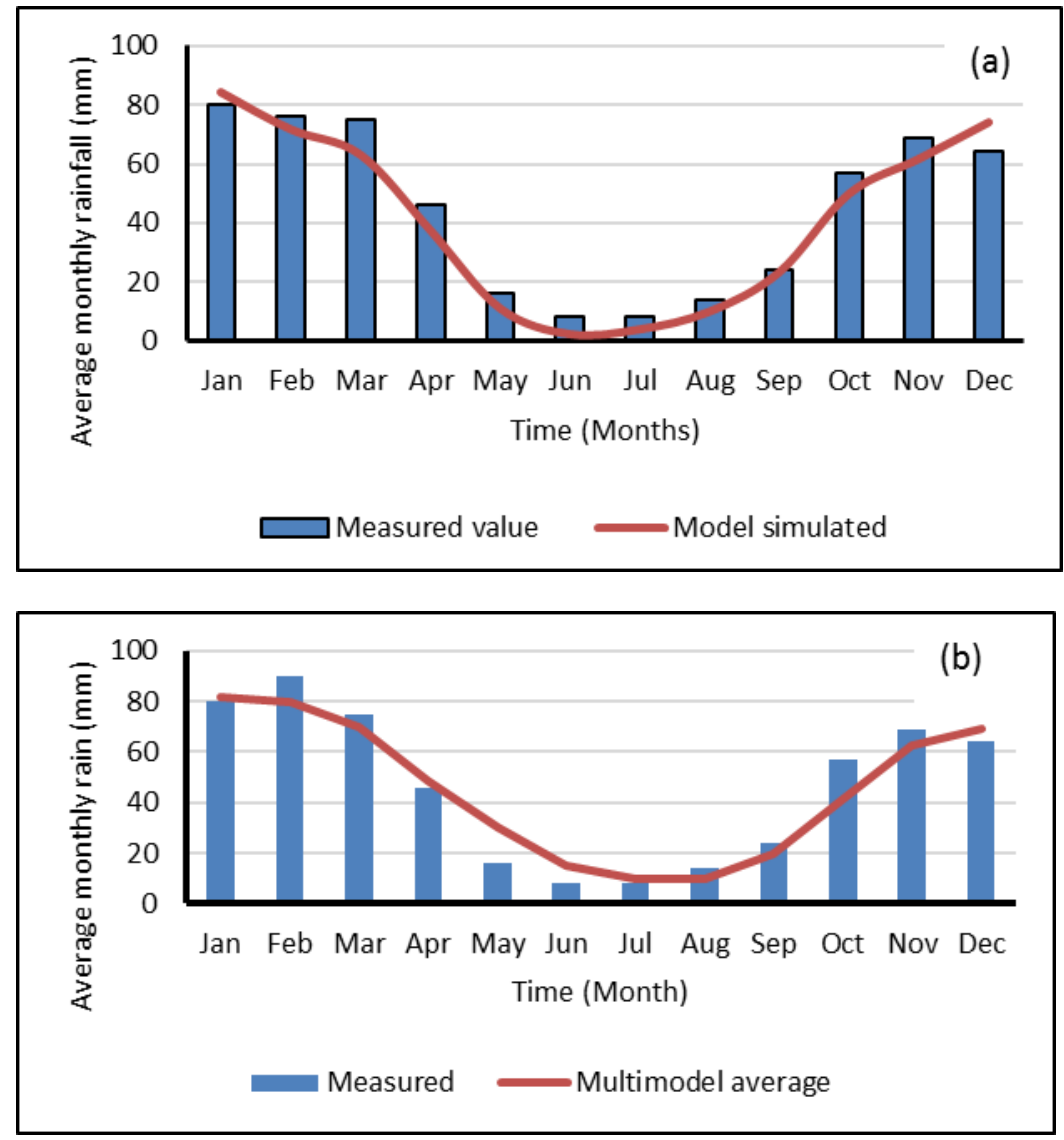

Fig. 1. Comparison of measured and simulated average historical monthly values of rain using multimodel average: (a) SDE; (b) CORDEX.

The projected decrease in rainfall is expected to have an impact on water balance components of the river basin. The assessment of impact of climate change on water balance components of the river basin showed varied results depending on the type of climate model used and the downscaling approach, but generally, the trends were similar in most cases (Figure $3 \mathrm{a}$ and $3 \mathrm{~b}$ ). In the case of the SDE approach, the multimodel average showed a possible decrease in precipitation (by $14 \%$ ), a decrease in water yield (by $15 \%$ ) and an increase in potential evapotranspiration (by $10 \%$ ). A similar trend was observed for the CORDEX approach, with a decrease in rainfall (by $3 \%$ ) and a decrease in water yield (by $13 \%$ ) and an increase in evaporation (by $22 \%$ ). The increase in evaporation in both cases is indicative of possible drought spells between rainy events.

\section{Conclusion}

The hydrological simulation as well as analysis of climate change data showed that there will be a reduction in rainfall and other river basin water balance components under both greenhouse gas emission scenarios, but the effect will be more pronounced under the RCP8.5. The expected decrease in rainfall coupled with increase in PET are going to be the two major drivers in exacerbating the existing problem of water scarcity in the region. For example, decrease in rainfall (according to SDE's approach) will result in the reduction of water storage in a reservoir (Rustfontein Dam) by about $28 \%$ of its full capacity. If the 
increase in PET is added to this scenario, the effect will be much more pronounced and there will be much more reduction in water storage.
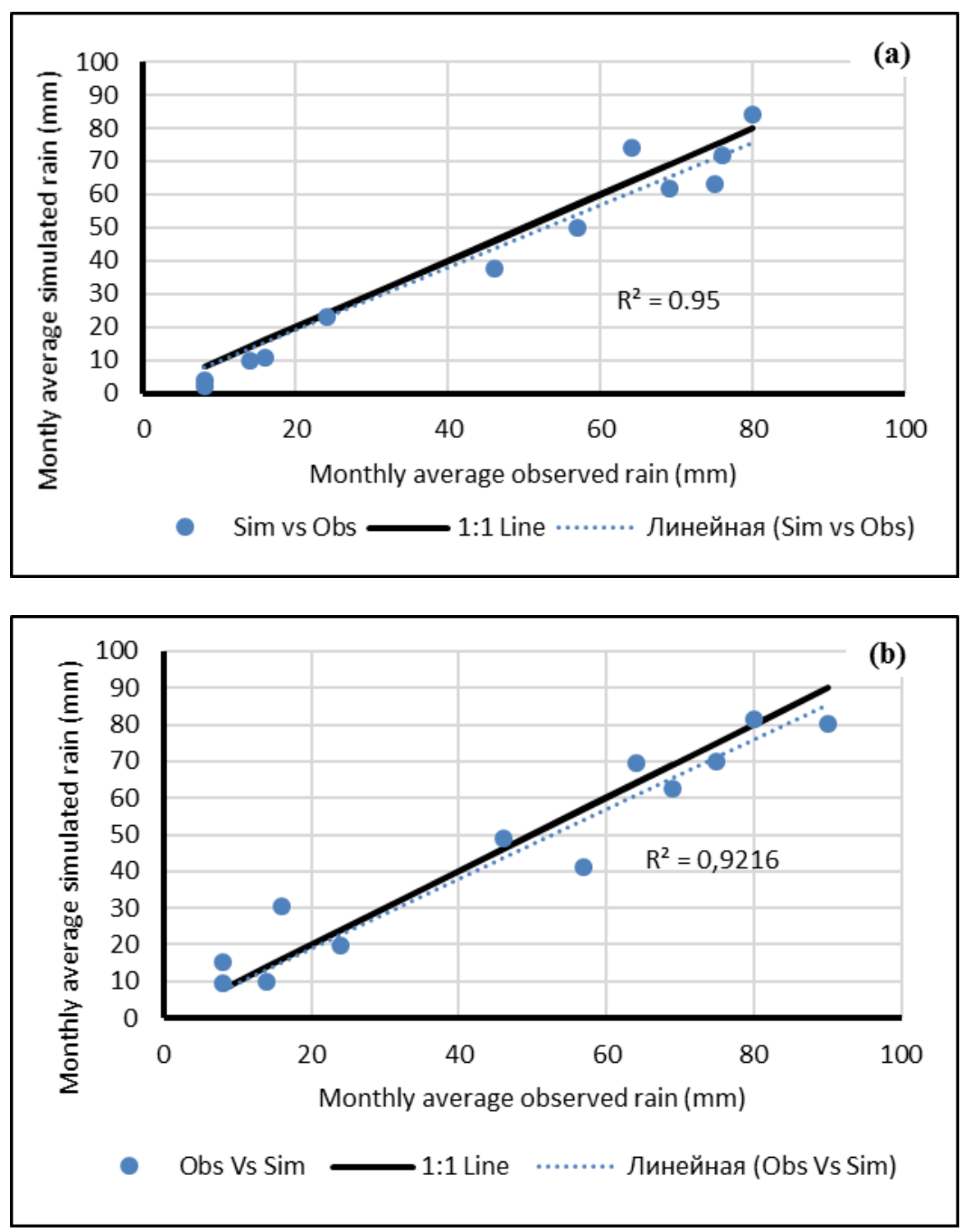

Fig. 2. Observed versus simulated average monthly values of rain using multimodel average: (a) SDE; (b) CORDEX.

Climate change has direct impact on water resources. Similarly, the management of water resources affects the vulnerability of ecosystems, socio-economic activities and human health. Climate change is projected to lead to major changes in water availability with increasing water scarcity and droughts mainly in the central region of South Africa. Water management is, therefore, expected to play an increasingly important role in adaptation to climate change. It is expected that the results of this research will assist in formulation of adaptation strategies that will minimize the negative impact of climate change in the region. 


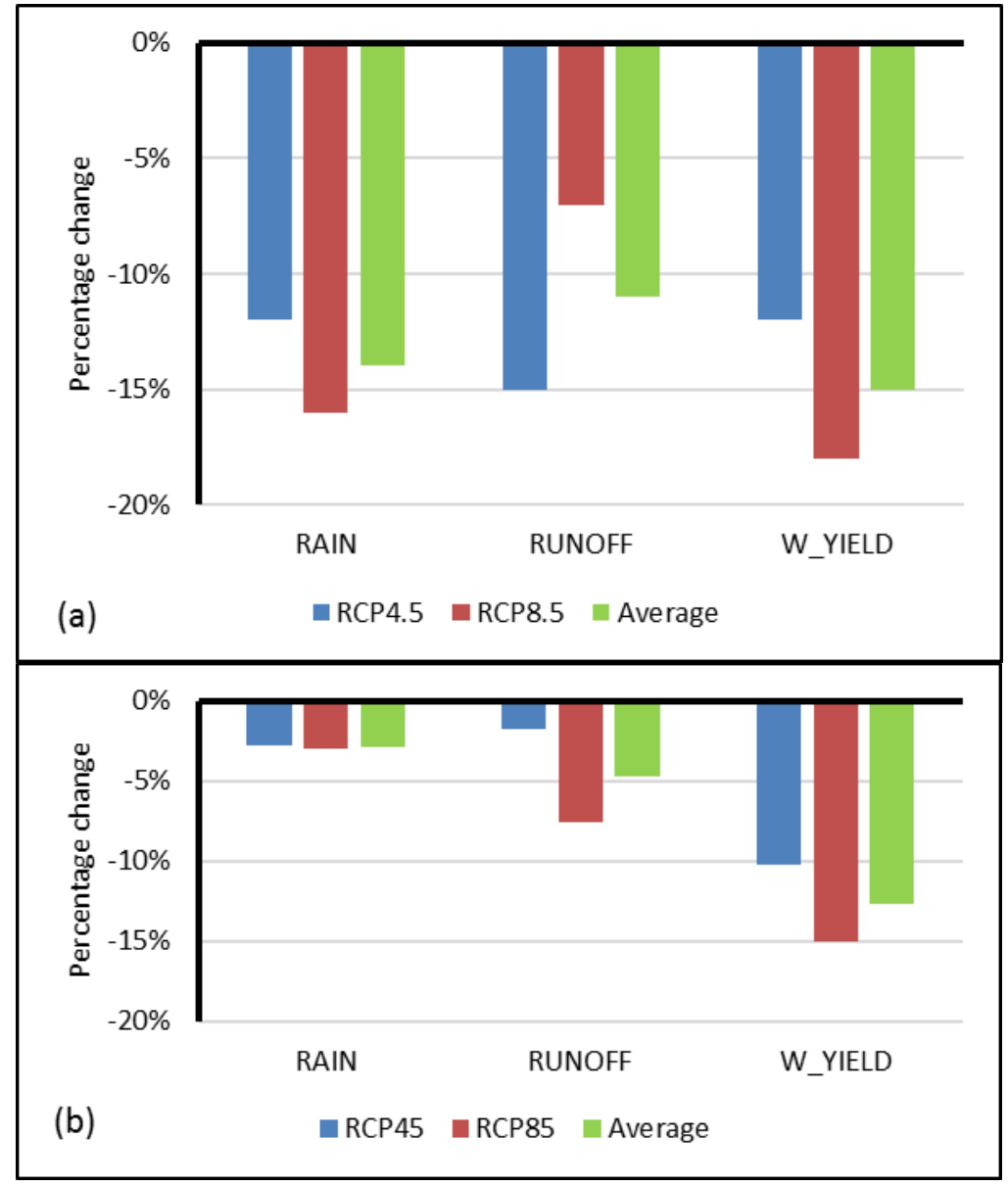

Fig. 3. Percentage change of future water balance components: (a) mid-century - SDE, (b) end of century - CORDEX.

\section{References}

1. AMCOW, Water security and climate resilient development: Technical Background Document (2012)

2. South African Department of Environmental Affairs, Climate trends and scenarios for South Africa, in Long Term Adaptation Scenarios (2013)

3. N. MacKellar, et al., South Afr J Sci, 110, 1-13 (2014)

4. E. Levina, Domestic Policy Frameworks for Adaptation to Climate Change in the Water Sector Part II: Non-Annex I Countries. Lessons Learned from Mexico, India, Argentina and Zimbabwe, OECD, Paris (2006)

5. World Water Council, World Water Vision: Making Water Everybody's Business, Earthscan Publications, London (2000) 